\title{
Markers of cell proliferation in a GH-producing adenoma of a patient treated with pegvisomant
}

\author{
W M Drake ${ }^{1}$, D M Berney ${ }^{2}$, K Kovacs ${ }^{3}$ and J P Monson ${ }^{1}$ \\ Departments of ${ }^{1}$ Endocrinology and ${ }^{2}$ Histopathology, St Bartholomew's Hospital, West Smithfield, London EC1A 7 BE, UK and ${ }^{3}$ St Michael's Hospital, \\ Department of Laboratory Medicine and Pathobiology, 30 Bond Street, Toronto, Ontario M5B 1W8, Canada
}

(Correspondence should be addressed toW M Drake; Email: w.m.drake@qmul.ac.uk)

\begin{abstract}
We report our findings on markers of cell proliferation (Ki-67 labelling index and topoisomerase- $\alpha$ expression) in a somatotroph pituitary tumour before and after exposure to pegvisomant, a GH receptor antagonist developed for the treatment of acromegaly. Specimens from two separate pituitary operations, separated by a period of 17 years that included 4 years of pegvisomant treatment, were stained for markers of cellular proliferation. Ki-67 labelling index and topoisomerase- $\alpha$ expression were both markedly greater $(1-3 \%$ compared with $0-0.5 \%$ and $15-80 \%$ compared with $2-10 \%$ respectively) in the pegvisomant-exposed tumour compared with the earlier specimen. Clearly, caution must be exercised when interpreting findings from a single case, particularly one sufficiently refractory to conventional therapies to require treatment with pegvisomant. However, our data reinforce the requirement for careful radiological surveillance of the pituitary in the context of a drug that does not target the tumour responsible and where serum GH cannot serve as a marker of disease activity or tumour size.
\end{abstract}

European Journal of Endocrinology 153 203-205

\section{Introduction}

Pegvisomant is a pegylated analogue of human growth hormone $(\mathrm{GH})$ licensed for use in the treatment of acromegaly $(1-3)$. Unlike other medical treatments, pegvisomant does not target the pituitary tumour responsible for excess GH secretion. Serum $\mathrm{GH}$ concentrations increase during pegvisomant therapy, probably as a result of increased pituitary secretion rather than decreased circulatory clearance (4), leading to speculation that pegvisomant therapy may be associated with a Nelson's syndrome-like effect (5), in which interruption of GH-mediated negative feedback leads to subsequent tumour expansion. Currently, there is no evidence that pegvisomant therapy causes an increase in pituitary tumour volume (3), but it should be remembered that pituitary tumours are often slow growing, and that Nelson's syndrome may develop after many years (4). Pituitary tumour immunohistochemistry before and after treatment with pegvisomant may provide early indication of the potential for this drug to provoke tumour enlargement. We report our findings on markers of cell proliferation in a somatotroph pituitary tumour before and after pegvisomant therapy.

\section{Case report}

Acromegaly was diagnosed, in 1976, in a 16-year-old girl with secondary amenorrhoea. The mean serum GH concentration was $\sim 400 \mathrm{mU} / \mathrm{l}$, decreasing to $\sim 150 \mathrm{mU} / \mathrm{l}$ with bromocriptine $40 \mathrm{mg}$ daily ('safe' $\mathrm{GH}$ concentrations for treated acromegaly are $<5 \mathrm{mU} / \mathrm{l}$ ). External pituitary irradiation was followed, shortly after, by probable pituitary apoplexy. In 1977, the patient underwent trans-sphenoidal surgery with removal of GH-staining adenoma. Between 1978 and 1986 there was massive expansion of the tumour through the right cavernous sinus into the infratemporal fossa, with an increase in serum GH from 42 to $>1000 \mathrm{mU} / \mathrm{l}$ and intractable trigeminal pain, requiring craniotomy and transfrontal resection of intra-cavernous-sinus tumour. The pain improved and serum GH concentrations decreased to $\sim 350 \mathrm{mU} / \mathrm{l}$. In 1988, the patient received stereotactic radiotherapy to an orbital extension of tumour, but the infratemporal portion could not be safely targeted. GH concentrations decreased to $\sim 200 \mathrm{mU} / \mathrm{l}$. In 1991, a nadir $\mathrm{GH}$ of $70 \mathrm{mU} / \mathrm{l}$ was achieved with subcutaneous octreotide $2500 \mu \mathrm{g}$ daily by continuous infusion. Treatment with cabergoline caused adverse psychological symptoms. Two cycles of chemotherapy (Iomustine and 5-fluorouracil) were unsuccessful. 
In 1997, the patient enrolled in a randomized trial, and pegvisomant $30 \mathrm{mg}$ weekly was commenced, with subsequent increments to $40 \mathrm{mg}$ daily during an open-label, daily-dosing phase (3), with good symptomatic and biochemical results. Treatment was suspended between 2000 and 2002 because of a shortage of the drug; during this period the patient received $30 \mathrm{mg}$ monthly of depot octreotide (Novartis), with symptomatic and biochemical deterioration (increased fatigue and sweating in association with a serum insulin-like growth factor (IGF)-I concentrations consistently greater than $1000 \mathrm{ng} / \mathrm{ml}$ ). After recommencement of pegvisomant in 2002, inadequate biochemical control was achieved with $40 \mathrm{mg}$ daily and the dose was increased to $60 \mathrm{mg}$. In 2003, the patient underwent transmaxillary removal of most of the infratemporal-fossa tumour extension. Symptomatic and biochemical improvement were immediate (reduced fatigue and sweating, normal serum IGF-I concentration). Progressive decrements in the dose of pegvisomant were made, indicating a reduced GH burden, but the patient developed a staphylococcal septicaemia and died. No source was identified at postmortem examination.

\section{Materials and methods}

Specimens from 1986 and 2003 were fixed in formalin, paraffin embedded, cut and stained for immunohistochemistry using the streptavidin-biotin-peroxidase complex method. No material was available for electron microscopic study.

\section{Results}

By histology, both tumours (Fig. 1) were atypical, partly acidophilic, partly chromophobic somatotroph adenomas showing marked cellular and nuclear pleomorphism. The tumour cells were immunoreactive for $\mathrm{GH}$, but immunonegative for the other adenohypophysial hormones (prolactin, adrenocorticotrophic hormone, thyroid-stimulating hormone, follicle-stimulating hormone, luteinizing hormone and alpha subunit). Minor differences included slightly more pronounced fibrosis, slightly greater expression of vascular endothelial growth factor (VEGF), slightly more intense GH immunoreactivity and decreased number of keratin-positive intracytoplasmic fibrous bodies in the post-pegvisomant tumour as compared with the tumour not exposed to pegvisomant. No differences were noted in the rate of mitosis, vascularity, cellular and nuclear pleomorphism, E-cadherin expression, S-100 protein and glial fibrillary acidic protein (GFAP) immunopositivity. Neurofilament antigen was negative in the tumour cells. Immunostainings for p53, cyclo-oxygenase-2, p27 and proliferating cell nuclear antigen yielded inconclusive results.

Two conspicuous differences between the specimens were apparent. Firstly, the Ki-67 labelling index (a marker of rate of cell proliferation) was markedly greater $(1-3 \%)$ in the pegvisomant-exposed tumour compared with the earlier specimen $(0-0.5 \%)$. Secondly, expression of topoisomerase $2 \alpha$ (another marker of cell proliferation) was greater in the second specimen (15-80\% compared with 2-10\%). This suggests that more cells proliferated in the tumour removed after pegvisomant treatment than in the

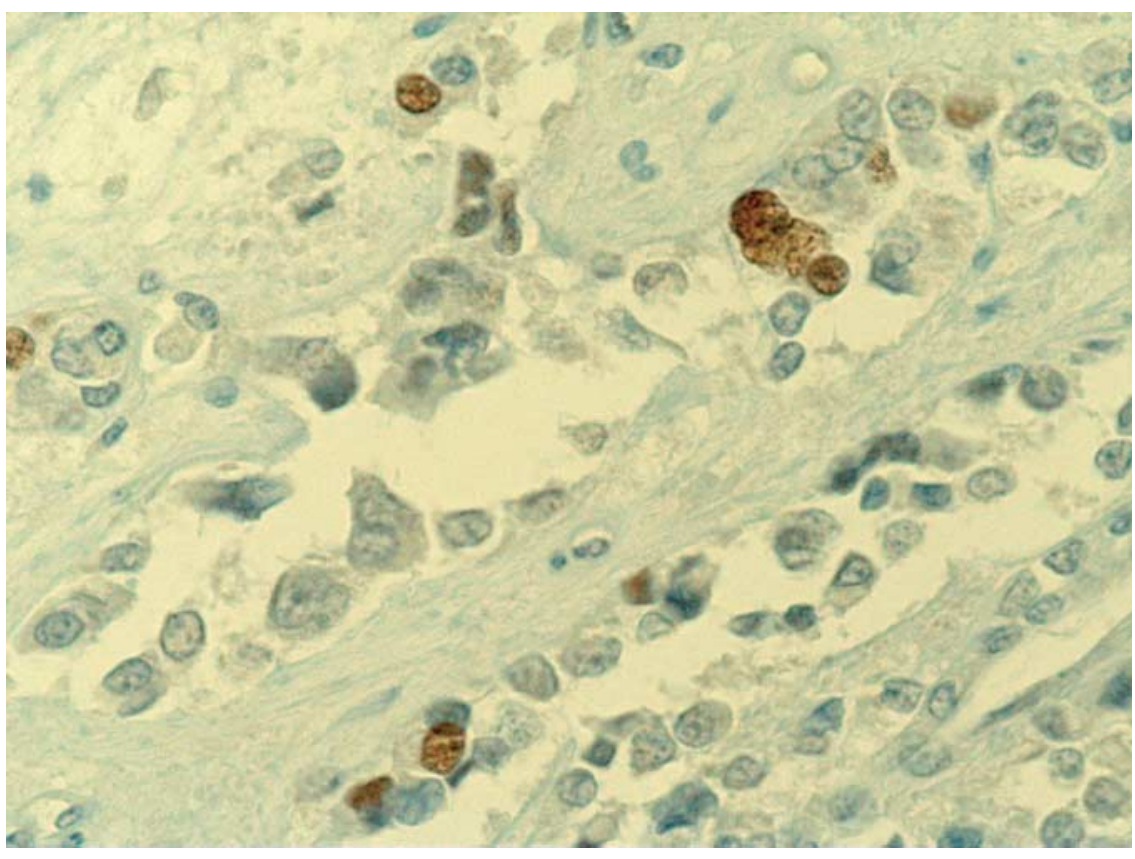

Figure 1 Topoisomerase $\alpha$ staining in a somatotroph tumour. (A) 1986 specimen. (B) 18 years later: pegvisomant therapy was received during the periods 1997-2000 and 2002-2004. 
1986 specimen. Marginally greater fibrosis, VEGF expression and $\mathrm{GH}$ immunoreactivity and slightly fewer keratin-positive intracytoplasmic fibrous bodies were noted in the tumour exposed to pegvisomant.

\section{Discussion}

To our knowledge, this is the first report of somatotroph pituitary tumour immunohistochemistry before and after exposure to pegvisomant. Although, to date, there is no evidence of a change in mean tumour volume in patients treated with pegvisomant (3), our findings raise the possibility that the drug may cause enhanced tumour cell proliferation and, by implication, subsequent accelerated tumour growth. Clearly, caution is needed when interpreting findings from a single case. It is possible that the tissue examined was not representative of the entire tumour. It must also be emphasized that 11 years elapsed between the 1986 craniotomy and the commencement of pegvisomant treatment in 1997, such that the changes reported above may have occurred during this period, independent of pegvisomant. Against this argument is the observation that the earlier specimen was obtained at a time of maximum tumour growth rate (serum GH increased from 42 to $>1000 \mathrm{mU} / \mathrm{l}$ and the infratemporal fossa was invaded after trans-sphenoidal surgery in 1978). After the 1986 craniotomy and subsequent stereotactic radiotherapy, tumour volume was relatively static, with only a $1 \mathrm{ml}(6 \%)$ increase after the commencement of pegvisomant.

It will take several years of follow-up to establish whether pegvisomant therapy is associated with accelerated tumour growth. Despite the limitations of our study, we feel it important to report the finding that the Ki-67 labelling index and expression of topoisomerase $2 \alpha$, both markers of cellular proliferation, increased over a period of time, during which our patient received pegvisomant. We encourage similar studies in other acromegalic patients exposed to pegvisomant. Careful radiological surveillance is clearly mandatory in the context of a drug that does not target the tumour responsible and where serum GH cannot serve as a marker of disease activity or tumour size.

\section{References}

1 Fuh G, Cunningham BC, Fukunaga R, Nagata S, Goeddel DV \& Wells JA. Rational design of potent antagonists to the human growth hormone receptor. Science 1992256 1677-1680.

2 van der Lely A, Hutson R, Trainer P, Besser G, Barkan A, Katznelson L, Klibanski A, Herman-Bonert V, Vance M, Freda P, Stewart P, Friend K, Clemmons D, Johannsson G, Stavrou S, Cook D, Phillips L, Strasburger C, Hacker S, Zib K, Davis R, Scarlett J \& Thorner M. Long-term treatment of acromegaly with pegvisomant, a growth hormone receptor antagonist. Lancet 2001358 1754-1759.

3 Trainer PJ, Drake WM, Katznelson L, Freda PU, Herman-Bonert V, van der Lely AJ, Dimaraki EV, Stewart PM, Friend KE, Vance ML, Besser GM \& Scarlett JA. Treatment of acromegaly with the growth hormone-receptor antagonist pegvisomant. New England Journal of Medicine 2000342 1171-1177.

4 Veldhuis JD, Bidlingmaier M, Anderson SM, Evans WS, Wu Z \& Strasburger CJ. Impact of experimental blockade of peripheral growth hormone $(\mathrm{GH})$ receptors on the kinetics of endogenous and exogenous GH removal in healthy women and men. Journal of Clinical Endocrinology and Metabolism 200287 5737-5745.

5 Nelson DH, Meakin JW \& Thorn GW. ACTH producing tumours following adrenalectomy for Cushing's syndrome. Annals of Internal Medicine 196052 560-569.

Received 8 April 2005

Accepted 10 May 2005 